\title{
AS FRONTEIRAS FÍSICAS DO ESPAÇO RURAL: UMA CONCEPÇÃO NORMATIVO-DEMOGRÁFICA ${ }^{1} 2$
}

\author{
The physical borders of the rural space: \\ a demographic-normative conception
}

\author{
Luis Almeida TAVARES ${ }^{3}$
}

\section{RESUMO}

O espaço rural brasileiro tem uma dimensão socioespacial, onde localizam atores sociais que historicamente constroem/ reconstroem sua realidade. Para sua análise predominam duas concepções: a normativa/demográfica, que não é utilizada pelo poder público brasileiro, mas usada nas análises por pesquisadores brasileiros, e é o critério que define o espaço rural em vários países europeus e latino-americanos; e a sociológica. Para sua melhor compreensão, partiu-se da origem dos municípios brasileiros, que vem do modelo da República Romana, de onde foi para a Península lbérica, e o governo colonial português transpôs para cá. Quanto às normas jurídicas que delimitam seu perímetro urbano, vigoram desde o Estado Novo, por meio do vigente Decreto-Lei 318, de 1938; portanto, a delimitação do espaço rural e urbano normativamente é anacrônica e anômala. Na conclusão apresentam-se notas preliminares de uma nova tipologia para os municípios rurais brasileiros.

\section{Palavras-chave:}

Dimensão do espaço rural, tipologia dos municípios rurais.

\begin{abstract}
The Brazilian rural space has a partner-dimension where social actors are located. These actors have built/rebuilt the reality. For the analysis of the rural space there are two main conceptions: normative/demographic, which is not used by the Brazilian public sector, but is used by Brazilian researchers, and it is the criterion used to define the rural space in several European and Latin American countries; and the sociological one. For better understanding, this analysis starts with the origin of Brazilian municipal districts, which were originated from the Roman Republic model, used in the Iberian Peninsula, and finally brought to Brazil by the Colonial Portuguese. In relation to juridical norms, Law number 318 delimits the urban perimeter since the "Estado Novo" period; therefore, the delimitation of the rural and urban space is anachronic and anomalous. At the conclusions, preliminary notes of a new typology for the Brazilian rural districts are presented.
\end{abstract}

\section{Key words:}

Dimension of the rural space, typology of the rural districts.

1 Os meus mais sinceros agradecimentos aos Profs. Drs. Luis Lopes Diniz Filho, Francisco de Assis Mendonça, do Departamento de Geografia da UFPR, e Ariovaldo Umbelno de Oliveira, do Departamento de Geografia da USP, pelas sugestões apresentadas.

2 Este artigo faz parte do Capítulo 1 da Dissertação de Mestrado em Geografia, 2002.

${ }_{3}$ Mestre em Geografia pela UFPR/Técnico do IBGE em Curitiba. Endereço Eletrônico: lat@ibge.gov.br 


\section{INTRODUÇÃO}

O texto tem como objetivo analisar a trajetória dos debates acerca do espaço rural brasileiro, onde identificam-se duas correntes: normativo-demográfica, que orienta os cálculos da "taxa de ruralização" e diversas abordagens em ciência regional, "principalmente em estudos sobre hierarquia, sistema e redes urbanas" (VEIGA et al., 2001, p. 1), e a abordagem social, que define o espaço rural como território construtor da ruralidade. É o que afirmam diversos autores como FERREIRA (1999, p. 147), KARAM (2001, p. 33) e WANDERLEY (2000, p. 4), que diferenciam os sentidos dos termos "rural" e "ruralidade" para se oporem ao conceito clássico de urbano-rural, empregado sobretudo pelas ciências sociais, mas não serão objeto de análise neste texto. Bem como, para contribuir com o debate sobre o rural brasileiro, apresentam-se as primeiras notas de uma tipologia em construção para os municípios rurais brasileiros.

A seguir, apresenta-se a construção teórica da concepção normativo-demográfica, na medida em que busca apreender a problemática do espaço rural brasileiro no contexto da modernidade, destacando sua operacionalidade como categoria de análise.

\section{A FORMAÇÃO DO MEIO RURAL BRASILEIRO}

A formação histórica do meio rural brasileiro apresenta diferenças marcantes em relação à do meio rural europeu e norte-americano, ao mesmo tempo em que ele é bastante parecido com o de outros países não desenvolvidos, principalmente com os da América Latina. Basta lembrar as funções específicas aqui assumidas historicamente pelas cidades, a vinculação da grande agricultura de origem colonial do mercado externo e a possibilidade de deserção da população por um vasto território, para entender a particularidade brasileira no que se refere à constituição e composição das sociedades locais, à relação campo/cidade e às relações entre o que é "agricultura" e o que é "rural". (WANDERLEY, 1999, p.18).

No Brasil, o meio rural foi historicamente percebido como constituindo um "espaço diferenciado", que corresponde a formas sociais distintas: as grandes propriedades rurais (fazendas e engenhos), os pequenos aglomerados (povoados) e padrões culturais específicos. Esses espaços, juntamente com as pequenas cidades do interior, tiveram um importante papel na história do povoamento brasileiro, como "pontos de apoio da civilização" (WANDERLEY, 1999). Contemporaneamente, as transformações introduzidas no meio rural brasileiro pelo processo de "modernização conservadora" da sociedade e da agricultura, iniciado depois da Segunda Guerra Mundial, levaram alguns autores a caracterizar esse período pela ocorrência de um "processo de urbanização do campo". (GRAZIANO DA SILVA, 1997, p. 56; CARNEIRO, 1998, p. 7).

Para compreender a concepção normativademográfica sobre as fronteiras físicas do espaço rural brasileiro, faz-se necessário anteceder uma discussão sobre a história da formação dos municípios brasileiros.

\section{A ORIGEM DOS MUNICÍPIOS BRASILEIROS}

Como unidade político-administrativa, os municípios brasileiros têm origem no modelo da República Romana, que os impôs às regiões conquistadas, como a Península lbérica, de onde, naturalmente, chegou ao Brasil-Colônia (IBAM, 2001, p. 3); (CIGOLINI, 2000, p. 56).

Inspirada no modelo romano, em que exercia funções políticas, legislativas e administrativas, tem-se a comuna portuguesa, base da organização municipal implantada em terras brasileiras.

Em 1584, a coroa portuguesa implantou o Governo Geral, como forma de unificar a administração e centralizar o poder político, e para tanto incentivou a formação de cidades e vilas, que possuíam estatutos jurídicos (Ordenações) que disciplinavam seu funcionamento. A administração dessas unidades era exercida pelas Câmaras, que sempre buscavam autonomia e independência administrativa em relação à Metrópole, o que foi alcançado pela Constituição de 1824. (CIGOLINI, 2000, p. 57; IBAM, 2001, p. 5).

Foi somente com a Constituição de 1824 que se iniciou a verdadeira história dos municípios brasileiros, "até então o que havia entre nós era o município português, transportado para cá”. (CIGOLINI, 2000). Mas, no que se refere à regulamentação das funções municipais, verifica-se que ela ocorreu somente em 1828, através de lei complementar que retirou a autonomia dos municípios. Com isto, os municípios brasileiros tiveram limitadas suas liberdades, atribuições e competências. Por outro lado, foi-lhes dada "margem para que se abrisse discussão em torno das suas disposições, originando o fantasma da autonomia que assombrou o período republicano". (CIGOLINI, 2000; BERNARDES; SANTOS; WALCACER, 1983, p. 18).

Para BERNARDES, SANTOS e WALCACER (1983, p. 15), até 1938 o Brasil não teve dispositivo legal que estabelecesse diferenças sequer entre cidade e vila. A mais antiga unidade territorial, a sede de freguesia, costumava ser arbitrariamente elevada à condi- 
ção de vila, ou mesmo diretamente à condição de cidade. Também surgiam vilas e cidades sem a prévia existência de freguesias. Tanto cidades quanto vilas podiam ser sedes de municípios.

\begin{abstract}
"Tradicionalmente, no Brasil, a decisão sobre a criação de uma vila ou cidade ou sobre a elevação de um aglomerado pré-existente a esta ou àquela condição sempre emanou de uma disposição governamental, que não se prendia a qualquer requisito formal. A sede de uma freguesia, a primitiva unidade territorial brasileira, podia ser elevada arbitrariamente à vila ou diretamente à condição de cidade, na Colônia como no Império. Também ocorreram fundações, numa ou noutra categoria, não precedidas de freguesias, a instalação de ambas sendo simultânea. Salvador, Rio de Janeiro e Filipéia foram erigidas diretamente em cidades ainda no século XVI e, nos séculos subseqüentes, outras assim seriam implantadas, como Belém e São Luiz, no norte, e Cabo Frio, no Rio de Janeiro, também fundadas no início do século XVII, e Petrópolis, já em meados do século XIX." (BERNARDES; SANTOS; WALCACER, 1983, p. 25).
\end{abstract}

Importante lembrar que, na Colônia, a Coroa se reservava o direito de elevar as vilas à categoria de cidade. Mas também podiam criar vilas os donatários ou seus representantes, desde que as terras estivessem sob sua jurisdição, sendo os limites geográficos demarcados pelos limites das freguesias, sempre que se tratasse de espaço com ocupação consolidada. Até existiam regras para que cidades e vilas pudessem exercer suas diferentes funções, mas a decisão de criar ou elevar uma localidade à categoria de vila, ou cidade, não obedecia a nenhuma norma. Com a República, alguns governos estaduais tomaram iniciativas de uniformizar seus respectivos quadros territoriais, mas foi só com o Estado Novo que surgiram as diretrizes básicas nacionais de divisão territorial, que continuam até hoje.

No que diz respeito à Divisão Territorial Brasileira, na qual o município é um dos componentes, podese afirmar que os excessos cometidos sob a Constituição de 1946, quanto à criação de municípios, foram corrigidos, em parte, pela Constituição de 1967, ao transferir para a União a tarefa de estabelecer os requisitos mínimos para tal criação (população, renda pública, forma de consulta às populações locais). A Lei Complementar $n^{\circ} 1$, de 09/11/67, estabeleceu os seguintes requisitos para a criação de novos municípios: a) população mínima de 10 mil habitantes ou não menos que cinco milésimos da população estadual; b) eleitorado não inferior a 10\% da população do município; c) centro urbano já constituído; d) número de casas superior a 200 (o que corresponde, geralmente, a uma população de mil habitantes); e) arrecadação, no último exercício, de cinco milésimos da receita estadual de impostos. Excluiu-se da Lei a criação de municípios nos Territórios Federais. (IBAM, 2001, p. 28).

Considerando ainda insuficientes os requisitos para criação de novos municípios, a União baixou o Ato Complementar no 46, de 07/02/69, pelo qual nenhuma alteração no quadro territorial do Estado poderia ser feita sem a prévia autorização do Presidente da República, ouvido o Ministério da Justiça. Durante dez anos, até a Emenda Constitucional oㅜ 11, de 12/10/79, nenhum município foi criado no país.

Três leis complementares posteriores praticamente devolveram a criação de municípios à situação anterior, alterando matéria sobre plebiscito e ano de criação do município, devolvendo aos Estados algumas atribuições na matéria e tornando obrigatória, pelas Câmaras Municipais, a aprovação da criação ou supressão de distritos, subdistritos e municípios, assim como o desmembramento do território municipal para anexação a outro município.

Nas constituições anteriores, o município não era expressamente mencionado como parte integrante da Federação, embora fosse pacífico para muitos doutrinadores que a Federação brasileira compreendia também os municípios.

A Constituição, promulgada no dia 05/10/88, liquidou com essa questão, inseriu expressamente nos artigos $1^{\circ}$ e $18^{\circ}$ o município como ente federativo, ocorrendo um avanço significativo no que diz respeito à continuidade do território municipal, que cedeu parte de seu território para a criação de um novo município. Deverá ser preservada a unidade histórico-cultural do ambiente urbano do município "mãe", a qual dar-se-á por lei estadual, obedecendo aos requisitos previstos em lei complementar estadual, e que dependerão de consulta prévia, mediante plebiscito, às populações diretamente interessadas.

Com a aprovação da Emenda Constitucional no 15, de 12/09/96, o $4^{\circ}{ }^{\circ}$ do Art. 18 da Constituição Federal passou a ter a seguinte redação: $A$ criação, a incorporação, a fusão e o desmembramento de Municípios, far-se-ão por lei estadual, dentro do período determinado por lei complementar federal, e dependerão de consulta prévia, mediante plebiscito, às populações dos Municípios envolvidos, após divulgação dos Estudos de Viabilidade Municipal, apresentados e publicados na forma da lei. Tal fato representou um retrocesso no que diz respeito à preservação da continuidade do território e do ambiente histórico-cultural do município, que cedeu parte do seu território para a criação do novo município. A Lei Complementar Federal citada no art. 4º ainda não foi promulgada, bem como o Plano de Viabilidade Municipal, até o presente, ainda não teve definido o seu con- 
teúdo e, tampouco, foi estabelecido quem o definirá, se a União ou os Estados.

\section{CONCEPÇÃO NORMATIVO - DEMOGRÁFICA DO ESPAÇO URBANO E RURAL BRASILEIRO}

O Decreto-Lei 311/38 conferiu aos Conselhos Nacionais de Geografia e de Estatística - hoje IBGE - a atribuição de estabelecer os requisitos mínimos para a elaboração dos perímetros urbanos e mapas municipais. Por meio de atos baixados por prefeitos, num período em que não funcionavam as Câmaras Municipais, consagrou-se a figura legal do Perímetro Urbano ou Limite Urbano. Mas a autonomia conferida aos Estados no período pós-1946 resultou na adoção de critérios variáveis e diversas interpretações sobre o que deveria ser o perímetro urbano. (BERNARDES; SANTOS; WALCACER, 1983, p. 47). Até os dias de hoje, o que continua definindo a área urbana do município é a Lei do Perímetro Urbano, de competência exclusiva da esfera municipal, servindo tanto para fins urbanísticos quanto tributários. É esse perímetro urbano que indica o limite oficial entre as áreas urbanas e rurais.

Segundo JARDIM, citado por BERNARDES, SANTOS e WALCACER (1983, p. 15 e 16):

"A delimitação do quadro urbano das sedes municipais e distritais consistiria na descrição simples e clara de uma linha, facilmente identificável no terreno, envolvendo o centro de maior concentração predial, no qual, via de regra, se localizam os principais edifícios públicos e se manifesta a vida comercial, financeira e social da sede e onde, em muitos casos, há incidência de impostos especiais, como, por exemplo, o décima urbana.

A delimitação do quadro suburbano das sedes consistiria na descrição de uma linha abrangendo uma área que circundasse o quadro urbano, área dentro da qual já se estivesse processando a expansão da zona urbana da sede ou que, por suas condições topográficas favoráveis, estivesse naturalmente destinada a essa expansão. A linha de contorno do quadro suburbano devia circunscrever o mais rigorosamente possível a área que correspondesse, realmente, à expansão ou próxima do centro urbano, sendo vedado delimitar-se, qualquer que seja o pretexto para isso invocado, mesmo a título de regularização da forma, um perímetro suburbano que se afastasse, em distância e conformação, da área de expansão acima referida".

No Brasil, não houve uma evolução normativa institucional significativa no que se refere à criação de municípios, distritos e à delimitação dos perímetros urbano e rural dos municípios. Em 1945, foi assinado o Decreto-Lei no 7.499 , de 9 de abril de 1945, pelo Governo Federal, que estabelecia a distinção entre os imóveis urbanos e rurais. O Art. 1으 $\S 2^{\circ}$, desse Decreto-Lei, dispôs sobre a organização da vida rural e definiu como estabelecimento rural "o imóvel situado dentro ou fora dos limites urbanos, que se destina ao cultivo da Terra [...]". (BERNARDES; SANTOS; WALCACER, 1983, p. 14).

Já as constituições pós-1946 disciplinam tão-somente a criação de municípios e distritos, e os critérios para a criação são estabelecidos por lei complementar. Mas as leis complementares são omissas no que se refere aos critérios de delimitação dos espaços urbanos e rurais dos municípios, o mesmo acontecendo com o novíssimo Estatuto da Cidade, de 2000. Por exemplo, ao dispensar da exigência de Plano Diretor quase todas as "cidades" com menos de 20 mil habitantes (VEIGA et al., 2001, p. 8). ${ }^{4}$

Outro problema diz respeito à legislação referente ao IPTU. A Constituição Federal de 1988, no capítulo "Da política urbana", o Código Tributário Nacional (art. 32), os Planos Diretores dos Municípios com mais de 20 mil habitantes e o recente Estatuto da Cidade permitem a cobrança de imposto, progressivamente, no tempo, de áreas incluídas no Perímetro Urbano ou Zona Urbana que não estejam edificadas ou que estejam subutilizadas ou não utilizadas (especulação imobiliária de terras urbanas). Uma vez que o fato gerador do IPTU é a propriedade predial e territorial urbana, e dada a autonomia dos municípios para delimitar o perímetro urbano, as atuais normas que delimitam os espaços urbano e rural no Brasil são tributaristas e, por isso, não levam em consideração as questões históricas e sociais da formação dos espaços urbano e rural. ${ }^{5} \mathrm{Em}$ virtude disso, a legislação acaba por subestimar os espaços rurais, classificando-os como urbanos, com vistas a expandir a base de arrecadação do IPTU.

${ }^{4}$ Essa é uma situação problemática, pois sabe-se que nas últimas décadas o território brasileiro passou por mutações significativas em razão de "acréscimos técnicos que renovam a sua materialidade, como resultados e condição, ao mesmo tempo, dos processos econômicos e sociais em curso" (SANTOS e SILVEIRA, 2001, p. 55). Seria razoável que, no início do século 21, o país contasse com normas legais de delimitação do espaço urbano e rural que refletissem as transformações ocorridas no território brasileiro.

5 Uma outra finalidade da delimitação dos perímetros urbanos municipais é evitar conflitos com a União, dado que a zona rural é objeto de competência tributária desta (Constituição Federal, art. 153, VI). 
Outra distorção decorre da não atualização dos perímetros urbanos por parte de muitos municípios, o que levou o IBGE a introduzir, para efeito de apuração e divulgação dos dados do Censo Demográfico de 1991 (e que continua valendo para o Censo Demográfico 2000), outras unidades territoriais além das três já tradicionalmente utilizadas, que eram as áreas "urbana", "rural" e "área urbana isolada". As novas unidades são: as "áreas especiais" (de conservação e preservação ambiental, comunidades indígenas, etc); os "aglomerados subnormais" (favelas e similares); os "aglomerados rurais isolados" (povoados, núcleos e lugarejos); as "áreas urbanizadas" (dentro do perímetro legal e que apresentam efetiva urbanização); "áreas não urbanizadas" (dentro do perímetro mas que não apresentam efetiva urbanização); e os "aglomerados de extensão urbana" (assentamentos externos ao perímetro urbano legal, mas desenvolvidos a partir da expansão de uma cidade ou sede distrital).

Na identificação dos "aglomerados rurais" (que nos interessam especialmente), dois critérios foram observados: o tamanho - número de domicílios igual ou superior a 51 - e a densidade - a distância entre os prédios não deve ultrapassar 50 metros, com exceção dos templos e estabelecimentos de comércio ou serviços, para os quais são aceitos até 150 metros. A partir daí se definem: a) os "aglomerados rurais" do tipo extensão urbana; pelo critério da contigüidade, a distância do núcleo principal (cidade ou distrito) ou de outro aglomerado rural de extensão urbana deve ser inferior a $1 \mathrm{~km}$, considerada a menor distância efetiva entre as duas áreas urbanizadas; b) os "aglomerados rurais isolados", quando essa distância for superior a $1 \mathrm{~km}$, que podem ser classificados como "povoado", (quando não são vinculados a um único proprietário do solo e possuem serviços para atender aos seus moradores); c) "núcleo", quando, independentemente de possuir ou não serviços, está vinculado a um único proprietário do solo; e d) "outros", quando não dispõem de serviços definidores de povoados e não estão vinculados a um único proprietário. Também foram consideradas como "áreas urbanas não urbanizadas" (sic) aquelas localizadas no interior dos perímetros legalmente definidos por lei como urbanos, mas que estavam ocupadas com atividades agropecuárias. As áreas ociosas contíguas às cidades e distritos e reservadas à expansão urbana foram consideradas como áreas urbanizadas, mesmo que não dispusessem de construções ou equipamentos urbanos. (IBGE, 1998, p. 19 a 21).

Essas "áreas urbanas não urbanizadas" são estoques de terras rurais para a especulação imobiliária, e os agentes imobiliários exercem uma forte pressão sobre as Câmaras Municipais para incluí-las no perímetro urbano, sobrepondo-se aos interesses do município.
Para SARACENO (1994, p. 354), essa definição do espaço rural pelo IBGE é de natureza residual, pois as áreas rurais são aquelas que se encontram fora dos limites das cidades, cujo estabelecimento é prerrogativa das prefeituras municipais. $O$ acesso à infra-estrutura $e$ serviços básicos e um mínimo de adensamento já são suficientes para que a população se torne "urbana", de modo que o meio rural corresponde às áreas remanescentes ainda não atingidas pelas cidades e sua emancipação social passa a ser vista de maneira distorcida como urbanização no campo.

A forma distorcida da urbanização no campo também é vista na esfera do planejamento municipal. Exemplificando, o município de Curitiba, desde 1980, não tem espaço rural, pois toda a sua área territorial é considerada como urbana; mas, de acordo com o Censo Agropecuário 1995/96, possuía 56 estabelecimentos agropecuários, com intensa atividade. Tal fato ocorre em muitos municípios brasileiros, na sua grande maioria sedes das capitais e cidades de grande porte.

SARACENO (1994, p. 348) resume bem o argumento: "O paradoxo da ruralidade é que ela é definida em termos negativos e só pode permanecer rural se não sofrer mudança ou se declinar. É impossível para uma área rural desenvolver-se sem que automaticamente se torne não-rural". A mesma autora nos diz que, enquanto o estudo do meio rural for a monótona confirmação da profecia sempre realizada de seu esvaziamento, será impossível compreender as razões que explicam a existência de áreas rurais dinâmicas, o que, "como mostram os trabalhos da divisão de desenvolvimento territorial da Organização de Cooperação e Desenvolvimento Econômico - OCDE (1994), compromete a própria concepção de políticas para as áreas mais atrasadas". ( $p$. 341).

ABRAMOVAY (2000, p. 4) e VEIGA et al. (2001, p. 6) afirmam que, atualmente, existem três maneiras predominantes na delimitação do rural, as quais são criticadas pela grande maioria dos pesquisadores, seja em âmbito nacional, seja em âmbito internacional:

1 - A delimitação administrativa ou normativa, que é utilizada no Brasil, já discutida anteriormente, é também usada em muitos países da América Latina, como Equador, Guatemala, El Salvador e República Dominicana.

Para o autor, as principais restrições que se podem fazer a essa abordagem seriam assim resumidas:

1.1 - O rural é definido, ao menos em parte, ao arbítrio dos poderes públicos municipais, em que as conseqüências fiscais da definição acabam sendo mais importantes que seus aspectos geográficos, sociais, econômicos ou culturais; 
1.2 - desde que haja extensão de serviços públicos a um certo aglomerado populacional, ele tenderá a ser definido como urbano. No Brasil, as sedes de distrito com algumas centenas ou dezenas de domicílios são definidas como "urbanas"; e

1.3 - o rural tenderá a ser definido, a princípio, pela carência, o que não pode ser considerado um critério adequado sob qualquer ponto de vista.

Para GRAZIANO DA SILVA et al. (1997, p. 45), esse problema tem sido contornado de maneira recorrente, principalmente por estudiosos e instituições responsáveis pelas estatísticas e políticas territoriais dos diversos países da Europa e Estados Unidos, por meio de categorias intermediárias, como "periurbano" (na França), "semi-rural", "campo urbanizado" e "novo rural". Segundo SARACENO (1994, p. 319), nas tentativas mais recentes da Divisão de Desenvolvimento Rural das Nações Unidas para Alimentação e Agricultura para América Latina, o rural não é definido por oposição e sim na sua relação com as cidades, mas como uma complementação, em que cada um não perde sua identidade socioeconômica e cultural.

2 - O peso econômico na ocupação de mão-deobra da agricultura: há países, como Chile e Israel, que utilizam esse critério como o principal para a delimitação do rural. No Chile, além do patamar populacional (1.500 habitantes) a localidade rural deve ter menos de $50 \%$ de seus habitantes ocupados em atividades secundárias. Em Israel, são consideradas urbanas as localidades onde 2/ 3 dos chefes de família exercem ocupações não agrícolas (ABRAMOVAY, 2000, p. 5).

Para o autor, caso esse critério fosse adotado em países desenvolvidos, seria extinto o espaço rural, ao mesmo tempo em que este espaço teria uma significativa diminuição de sua importância na noção de desenvolvimento, e cita o exemplo das estatísticas francesas, que registram que $27 \%$ da população do país vive no meio rural e "apenas $13 \%$ de cada 100 habitantes dependem fundamentalmente da agricultura". E diz mais: "estas cifras não são muito distantes das que caracterizam a maior parte dos países industrializados. Em todos os países em desenvolvimento o trabalho não-agrícola cresce mais que o agrícola no meio rural".

2 - Um certo patamar populacional (ABRAMOVAY, 2000 , p. 5) cita vários países, como Espanha, Portugal, Itália e Grécia, que adotam esse critério para definir seus espaços rurais.
"[...] são rurais os habitantes que vivem em assentamentos humanos que reúnem em habitações contíguas ao menos 10 mil habitantes - e guardam uma certa distância dos centros metropolitanos, bem entendido [ver Bartolomé (1996, p. 55) e Arnalte (1998)]. Na França, são rurais as "comunas" com população inferior a 2 mil habitantes, critério estipulado ainda no século XIX".

Vários países latino-americanos (Argentina, Bolívia, México, Venezuela, Honduras, Nicarágua e Panamá) adotam igualmente um limite populacional que varia entre 1.000 a 2.500 habitantes na definição da população rural.

Segundo SARACENO, citado por ABRAMOVAY (2000, p. 12), a Organização de Cooperação e Desenvolvimento Econômico (OCDE), por exemplo, vem utilizando um esquema de divisão territorial com três níveis, combinando critérios demográficos. Para os 26 países membros, cerca de 50 mil comunidades locais são agrupadas de acordo com a densidade demográ-fica ${ }^{6}$ em 2.000 regiões, classificadas como: "predominantemente rurais" (mais de $50 \%$ da população vivendo em comunidades rurais); "significativamente rurais" (entre 15\% e 50\%) e "predominantemente urbanizadas" (abaixo de 15\%).

Já na França criou-se a categoria "periurbano" para designar comunidades rurais localizadas em volta de cidade. Seu crescimento seria interpretado apenas como alargamento das atividades urbanas, dando continuidade ao padrão anterior das migrações. Nessa categoria estão incluídas todas as comunidades industriais com no mínimo 100 empregos industriais, e uma empresa com no mínimo 20 assalariados. O rural é restrito a comunidades com menos de 2.000 habi-tantes em áreas contíguas e sem nenhuma indústria relevante.

Uma outra estratégia foi seguida pelos italianos. O Instituto de Estatística Italiano (ISTAT) dividiu a população em quatro categorias: rural, semi-rural, semi-urbana e urbana, mas essas categorias nunca foram usadas em pesquisas relevantes, embora o Instituto possua estatísticas detalhadas sobre elas. Para SARACENO (1994, p. 301), o problema é que a dicotomia rural-urbano não atende mais às necessidades teóricas de explicar as diferenças regionais na Itália, aparecendo o tamanho das comunidades como uma variável muito mais relevante. $\mathrm{Na}$ Itália, são rurais os habitantes que vivem em assentamentos humanos que reúnem em habitações contíguas ao menos dez mil habitantes.

Para ABRAMOVAY (2000), esse tipo de critério é certamente menos impróprio do que a delimitação administrativa:

\footnotetext{
${ }^{6}$ Se tiver menos de 150 habitantes por $\mathrm{km}^{2}$, a comunidade é definida como rural. Para o Japão, o limite é de 500 hab/km².
} 
"Já que evita que se assimile forçosamente o rural ao isolado: a maior parte das sedes de distritos brasileiros, por este critério, seria classificada como rural. Da mesma forma, caso se adotasse a classificação italiana, mais de 2.200 municípios brasileiros passariam a ser rurais. A adoção do limite de 20 mil habitantes parâmetro freqüente em organizações internacionais e proposta pelo sociólogo francês Henri Mendras (1995) - ampliaria de $22 \%$ para $33 \%$ a população rural brasileira" (p. 5).

Resumidamente, ABRAMOVAY (2000) afirma que existem alguns inconvenientes básicos com relação a essa definição do meio rural:

a) os limites estabelecidos internacionalmente são arbitrários - correspondem muito mais à tradição histórico-institucional que a situações geográficas refletidas;

b) a comparabilidade internacional das informações sobre o rural fica seriamente comprometida. Ele diz que tal localidade ou tal município é ou não rural (segundo os critérios estipulados), mas não dá a possibilidade de dizer se existem regiões ou territórios mais ou menos rurais;

c) esse critério não dá oportunidade para construir uma abordagem regional da ruralidade.

CARNEIRO (1997) tem uma visão bastante crítica tanto da idéia de dicotomia (extremos) como da de continuum entre urbano e rural. Ela recorre a autores que sustentam a necessidade de analisar o rural centrandose nas relações sociais e argumenta:

"Orientar o foco de análise para os agentes sociais deste processo (de decomposição e recomposição de sistemas sociais) e não mais para um espaço geográfico rarefeito possibilita, por exemplo, que a distinção entre "cidade" e "aldeia" e "rural" desapareça ou torne-se inútil como questão sociológica. Isso porque cada espaço contém em si contradições e conflitos resultantes da relação entre sistemas de valores distintos, quer sejam eles tidos como de origem "urbana" ou "rural". (p. 155).

Nesse sentido, a ruralidade não é uma realidade "empiricamente observável", mas uma "representação social", definida culturalmente por atores sociais. Por isso, a autora propõe a noção de "localidade" como expressão das múltiplas formas de interação desses atores (que desempenham atividades heterogêneas, agrícolas ou não) com a sociedade e a economia global: "[...] a noção de localidade [...] denota apenas a referência espacial como qualificadora de um universo de relações sociais específicas. Em outras palavras, a noção não define, de forma alguma, a natureza rural ou urbana do grupo ou das práticas e relações sociais que ele desenvolve" ( $p$. 162).

ABRAMOVAY (1999, p. 16) argumenta que hoje existe um grande entendimento na literatura interna-cional em torno de três aspectos básicos sobre o meio rural, que são: a) a relação com a natureza; b) a importância das áreas não densamente povoadas; e c) a dependência do sistema urbano.

No Brasil, por questões político-administrativas ou normativo-jurídicas e geográficas, como pôde ser observado anteriormente, existe dificuldade para delimitar 0 espaço rural pelo critério do tamanho da população. FARIA (1984; 1991), ao analisar a estruturação do espaço urbano brasileiro, diz que ele é portador de uma dupla característica.

"Por um lado, concentra grandes contingentes populacionais - em termos de tamanho - em um número reduzido de áreas metropolitanas e grandes cidades como Rio de Janeiro, São Paulo, e outras áreas metropolitanas e capitais regionais e sub-regionais; por outro, alimenta o crescimento da população urbana de um número grande - e crescente - de cidades de diferentes tamanhos (grifo nosso) que se integram num complexo padrão de divisão territorial do trabalho social tanto entre o campo e a cidade como entre as cidades". (1991, p. 103).

No que se refere ao tamanho, FARIA (1984, p. 124) define como cidades aquelas "sedes municipais com mais de 20.000 habitantes" e como população urbana a que corresponde às pessoas vivendo nessas sedes. Também George Martine, citado por WANDERLEY (1999, p. 10; 2001, p. 4), "considera que apenas as aglomerações de 20.000 habitantes ou mais podem ser chamadas de cidades". Já LOPES, também citado por WANDERLEY (1999, p. 13), propõe que as aglomerações urbanas não tenham menos de 5.000 habitantes, porque uma parcela importante da população rural brasileira vive nos pequenos municípios, ou seja, este limite permite demarcar a área onde mais intensamente se faz sentir a influência de valores, padrões e formas de organização urbanos. ${ }^{7}$

7 Já CAMARANO e BELTRÃO, em trabalho recente, citado por WANDERLEY (2001, p. 4), assumem que apenas as aglomerações urbanas com 20 mil habitantes podem ser consideradas como cidades, o que foi proposto por FARIAS (1984). Para as autoras, "a definição de população urbana tem um caráter político-administrativo ao incluir todas as sedes de municípios e distritos, independentes do seu tamanho." Nesta perspectiva as autoras não consideram as cidades com população inferior a este limite, como integrante ao "sistema de cidades", sendo consideradas como "não-urbanas". 
Em todas essas proposições estão embutidos simplesmente o elemento demográfico (tamanho da população do município), o que as torna insatisfatórias para a análise do espaço rural, por não considerarem os elementos históricos, sociológicos e geográficos, tais como: o surgimento de cidades em decorrência do avanço das "Frentes Pioneiras e Fronteiras Agrícolas" e a vocação agrícola das regiões onde surgiram estas cidades (mesmo sabendo-se que o atual rural brasileiro já não comporta mais somente as atividades agropecuárias).

Hoje, vê-se que, pela dinâmica social, cultural e econômica do território brasileiro, uma análise dos municípios em uma abordagem somente demográfica torna-se frágil, pois não dá conta de algumas especificidades vocacionais de pequenos municípios. Por exemplo, municípios em que todo o cotidiano de seus agentes (sociais, culturais e econômicos) está voltado para o turismo rural ou extrativismo. ${ }^{8}$

Com efeito, não se deve mais definir o espaço rural exclusivamente como aquele onde predomina a atividade agrícola, principalmente em regiões dinâmicas, pois esta não tem mais o mesmo peso que nos anos 40 a 70, por existir um significativo contingente da população rural ocupada em atividades não agrícolas.

Como afirma PEREIRA DE QUEIROZ (1973), "os processos de persistência e mudanças do comportamento tradicional nos centros urbanos brasileiros estavam fortemente ligados ao meio agrário em que se localizam." Além disso, nossas "Frentes Pioneiras se apresentam com verdadeiros 'viveiros' de concentrações urbanas em processo de instalação, mostrando que 0 enriquecimento do campo continua a ser gerador de cidades" (p. 123).

Para ABRAMOVAY (1998, p. 15), não é mais possível afirmar que o espaço rural brasileiro concentra os piores indicadores de desenvolvimento, pois os índices do IDH-M (PNUD/IPEA, ${ }^{9}$ 1998) revelam que está havendo uma melhoria relativa na qualidade de vida da população nos municípios eminentemente rurais. Para que sua consolidação ocorra, é necessário que se leve também em consideração a noção de desenvolvimento rural, o valor da própria ruralidade, e não a idéia nefasta de que a emancipação das populações rurais passa pela intensificação dos processos migratórios, mesmo sabendo-se que o meio rural só pode ser compreendido em suas relações com as cidades, com as regiões metropolitanas e também com os pequenos centros em torno dos quais se organiza a vida local.

Como pode ser observado na Tabela 1, dos dez municípios com melhor IDH-M, apenas Porto AlegreRS, na $7^{a}$ posição, é uma Aglomeração Metropolitana, e três municípios (Florianópolis-SC, Santos-SP, Ribeirão Preto-SP) são considerados Aglomerações NãoMetropolitanas. Os outros seis municípios com população inferior a 50 mil habitantes são considerados rurais, de acordo com a tipologia do IPEA/IBGE/NESURUNICAMP (1999, p. 24, 65). Feliz-RS, com o melhor IDH-M, tinha 15.565 habitantes e um índice de urbanização de 53,72\% em 1991, Parai - RS, na 5 $5^{\text {a }}$ melhor colocação no IDH-M de todos os municípios brasileiros, tinha uma população de 5.110 habitantes e um índice de urbanização de apenas $25,75 \%$, conforme os atuais critérios de delimitação do espaço urbano e rural.

Portanto, nem todas as aglomerações providas de um mínimo de serviços podem ser adequadamente chamadas de espaço urbano. Assim, sendo, o IBGE poderia repensar a metodologia usada para definir 0 espaço urbano e rural, pois as atuais definições de urbano e rural contribuem para acentuar a percepção de esvaziamento do espaço rural.

Hoje, no Brasil, há várias tipologias de municípios brasileiros, pois, como afirma GRAZIANO DA SILVA (2001, p. 20), "não se pode dizer que uma tipologia seja 'melhor' ou 'pior' que a outra sem explicitar o seu objetivo. Ou seja, a tipologia depende do uso que queremos fazer dela".

\footnotetext{
${ }^{8}$ Um caso concreto é o Município de Maragogi-Al, onde, depois da instalação de um complexo hoteleiro, uma porcentagem significativa de sua população está exercendo atividades voltadas para o turismo, como proprietários de pousadas, garçons, cozinheiros(as), faxineiros e outras.

${ }^{9} \mathrm{O}$ Índice de Desenvolvimento Humano (IDH) é um indicador do nível de atendimento, em uma dada sociedade, das necessidades humanas básicas. Apesar da complexidade envolvida na identificação dos aspectos de maior relevância para o bem-estar de um indivíduo, - IDH incorpora três deles, quais sejam: vida longa e saudável, acesso ao conhecimento e padrão de vida digno. Na composição desse índice, cada um desses aspectos é representado por uma variável específica e mensurável: expectativa de vida ao nascer, nível de instrução e nível de renda. Ao levar em consideração as duas primeiras, o IDH inova em relação ao PIB per capita. A combinação destes índices, ponderados igualmente, gera um indicador síntese que tem a seguinte tipologia: de 0 a 0,50 - Baixo Desenvolvimento Humano; +0,50 a 0,80 - Médio Desenvolvimento Humano e +0,80 a 1 - Alto Desenvolvimento Humano.

O IDH-M foi construído com o objetivo de ser um índice apropriado para medir o desenvolvimento humano de municípios. Para tal, foram necessárias algumas adaptações metodológicas e conceituais em relação ao IDH. A composição do IDH-M depende das informações dos Censos Demográficos (IBGE), que são realizados a cada dez anos. O IDH-M foi calculado para os três últimos censos de 1970, 1980 e 1991 e sua atualização só será feita quando estiverem disponíveis os dados do Censo 2000. (PNUD/FJP/IPEA, 1998, p. 1).
} 
TAVARES, L. A. As fronteiras físicas do espaço rural: uma concepção...

\begin{tabular}{|c|c|c|c|c|c|c|c|c|}
\hline \multirow[t]{2}{*}{ Posição } & \multirow[t]{2}{*}{ Municípios } & \multirow{2}{*}{$\begin{array}{l}\text { IDH-M } \\
1991\end{array}$} & \multicolumn{3}{|c|}{1991} & \multicolumn{3}{|c|}{2000} \\
\hline & & & TOTAL & URBANA & RURAL & TOTAL & URBANA & RURAL \\
\hline $1^{\circ}$ & Feliz*-RS & 0,834 & 15.565 & 8.362 & 7.203 & 10.319 & 7.976 & 3.343 \\
\hline $2^{\circ}$ & Florianópolis-SC & 0,833 & 255.390 & 239.996 & 15.394 & 331.784 & 321.778 & 10.006 \\
\hline $3^{\circ}$ & Santos-SP & 0,830 & 428.923 & 427.273 & 1.550 & 417.777 & 415.543 & 2.234 \\
\hline $4^{\circ}$ & Indaial-SC & 0,829 & 30.158 & 28.234 & 1.924 & 40.100 & 38.286 & 1.814 \\
\hline $5^{\circ}$ & Parai-RS & 0,826 & 5.110 & 1.316 & 3.794 & 6.015 & 2.816 & 3.199 \\
\hline $6^{\circ}$ & Ribeirão Preto-SP & 0,825 & 436.682 & 426.819 & 9.863 & 505.012 & 502.333 & 2.679 \\
\hline $7^{\circ}$ & Porto Alegre-RS & 0,825 & 1.263 .403 & 1.247 .529 & 15.874 & 1.359 .932 & 1.320 .069 & 39.863 \\
\hline $8^{\circ}$ & Gaspar-SC & 0,825 & 35.614 & 23.364 & 12.250 & 46.377 & 29.586 & 16.792 \\
\hline $9^{\circ}$ & Videira-SC & 0,846 & 35.922 & 27.234 & 8.688 & 41.543 & 35.743 & 5.800 \\
\hline $10^{\circ}$ & Timbó-SC & 0,770 & 23.806 & 19.155 & 4.651 & 29.295 & 26.706 & 2.589 \\
\hline
\end{tabular}

FONTE: PNUD/IPEA/FJP - 1998 E CENSO DEMOGRÁFICO 1991 E 2000 - IBGE.

*NOTA: ENTRE 1991 E 1993 FORAM CRIADOS E INSTALADOS 94 MUNICÍPIOS NO ESTADO DO RIO GRANDE DO SUL. FELIZ CEDEU PARTE DE SEU TERRITÓRIO E POPULAÇÃO PARA A CRIAÇÃO DO MUNICÍPIO DE ALTO FELIZ.

Das várias tipologias dos municípios brasileiros existentes, escolheram-se, para fazer uma análise sintética, as seguintes:

VEIGA et al. (2001) tecem algumas críticas ao trabalho "Caracterização e Tendências da Rede Urbana do Brasil" (IPEA/IBGE/NESUR-UNICAMP, 1999), que cria categorias de aglomerações urbanas que integram a rede urbana brasileira, que são as seguintes:

1 - Aglomeração Metropolitana - composta por 200 municípios e agregava 57,4 milhões de habitantes em 2000, o que representava $33,9 \%$ de toda a população brasileira;

2 - Aglomeração Não-metropolitana - formada por um conjunto de 178 municípios e contava com um contingente populacional de 22,7 milhões de habitantes e representava $13,4 \%$ de toda a população brasileira em 2000; e

3 - Centros Urbanos - formados por um conjunto de 77 municípios e agregavam 16,1 milhões de habitantes, o que representava $9,5 \%$ do total da população brasileira. Ressalta-se que todos os municípios inclusos nestas categorias tinham populações superiores a 100 mil habitantes, em 2000.

Pelo que ficou demonstrado acima, e pelos critérios e metodologia adotados pelos autores para a construção dessa tipologia, pode-se dizer que o urbano bra- sileiro é formado por 455 municípios ou $8,26 \%$ dos 5.507 municípios existentes em 2000 , e concentra $56,78 \%$ da população brasileira.

Segundo CASTELLO BRANCO, citado por VEIGA et al. (2001, p. 8), os estudos para identificação de aglomerações urbanas levam em conta três aspectos: de natureza demográfica, de estrutura ocupacional e de integração entre os núcleos. Os demográficos são: o tamanho da cidade central ou cidades centrais e a densidade do núcleo e seu entorno - no trabalho acima é usado o critério de 60 hab./km², que foi proposto por Davidovich e Lima, em 1975. Os de estrutura referem-se ao caráter urbano das atividades econômicas desempenhadas pela população - $65 \%$ da PEA $^{10}$ dos municípios precisa estar ocupada nos setores secundário e terciário ou em "atividades urbanas" - percentual também proposto por Davidovich e Lima (1975). E os de integração referem-se ao deslocamento diário da população entre o(s) núcleo(s) e a periferia da aglomeração - movimento pendular da população.

VEIGA et al. (2001, p.12), fazem duas importantes críticas ao trabalho do IPEA/IBGE/UNICAMP, quais sejam: o critério de identificação do espaço com o setor primário da atividade econômica seria aceitável se hoje a participação dos outros dois setores (secundário e terciário) no espaço rural fosse irrisória. Mas, atualmente, a participação (principalmente) do setor de serviços como lazer, hotelaria, alimentação, etc. tem uma pene-

${ }^{10}$ PEA - População Economicamente Ativa. 
tração no "novo rural brasileiro" bem expressiva. "E num contexto em que todas as sedes municipais e distritais são urbanas, e qualquer aglomerado de 30 moradias pode ser elevado à categoria de vila (sede de distrito) e de 200 à categoria de cidade (sede municipal), nada mais coerente do que confundir o espaço rural com o setor agropecuário".

A outra crítica é em relação aos aspectos metodológicos tradicionais do uso da densidade de 60 hab./ $\mathrm{km}^{2}$ como critério da "concentração/rarefação populacional", que é utilizado desde 1975, quando foi proposto por Davidovich e Lima. "São critérios que só podem atrapalhar a construção de tipologias que captem a diversidade territorial dos $43,2 \%$ da população que está fora dessa rede". Os autores sugerem uma densidade demográfica média de 80 hab./ $\mathrm{km}^{2}$ para as aglomerações metropolitanas, não-metropolitanas e centros urbanos.

Para corroborar as críticas feitas pelos autores, pode-se dizer, segundo VILELA (1991, p. 56), que na segunda metade do século XX houve uma queda de um vigésimo nas atividades primárias, enquanto as atividades terciárias aumentaram sua participação no PIB, passando de um quarto para mais de três quintos, e as secundárias caíram para um pouco mais de um terço, nas economias mais desenvolvidas. Para os autores, essas são as tendências históricas estruturais dos três setores em que se convencionou separar o sistema econômico e não suas manifestações espaciais.

Como afirmam VEIGA et al.:

"O fato de atividades primárias estarem forçosamente muito mais presentes nas zonas rurais não significa que os outros dois tipos sejam necessariamente muito mais recorrentes nas zonas urbanas. O emprego industrial é mais significativo nas regiões relativamente rurais que nas essencialmente urbanas, chegando mesmo a ser muito mais rural que urbana em países nórdicos, como a Noruega e a Suécia. E os serviços têm quase o mesmo peso em regiões essencialmente urbanas e relativamente rurais, sendo extraordinariamente importantes nas regiões essencialmente rurais da Bélgica.[...] (VEIGA et al., 2001, p. 11)

É muito importante entender, então, que no capitalismo mais avançado o desenvolvimento de uma região rural há muito tempo deixou de depender de sua agricultura".

Ou seja, as economias rurais dinâmicas são as polivalentes, tornando os setores secundário e terciário muito mais decisivos que o primário. Espaços onde 0 domínio é das atividades primárias muito especializadas travam a diferenciação da economia e são exatamente os que permanecem subdesenvolvidos, mesmo quando fazem parte das nações mais desenvolvidas. O Brasil depende de sua agricultura, pois a agropecuária ainda é a parte decisiva da economia rural, tanto no que se refere à ocupação, como na geração de riquezas em espaços rurais não dinâmicos. (VEIGA et al., 2001, p. 13)

Quem são estes 5.052 ou $91,74 \%$ municípios brasileiros que em 2000 não pertenciam às Aglomerações Metropolitanas, Não-metropolitanas e Centros Urbanos? Em que espaços se encontram as 73,3 milhões de pessoas que estão residindo fora dessas aglomerações e centros urbanos?

Provavelmente as respostas estejam na importante contribuição de VEIGA et al. (2001), ao construir uma tipologia para os 5.052 municípios que tinham uma população inferior a 100 mil habitantes em 2000, a qual, acredita-se, é um importante passo para chegar a uma delimitação do espaço rural brasileiro que englobe as sugestões apresentadas anteriormente.

Os autores dividem em duas categorias esses 5.052 municípios, quais sejam: "Rurbano" e Rurais, com base em três variáveis: a localização, a densidade demográfica e o tamanho. Ao proporem essas categorias, colocou-se em cheque o conceito de população urbana e rural adotado pelo IBGE e identificaram-se 467 municípios Rurbanos, que abrangem perto de $60 \%$ do total da população brasileira em 2000, nos seguintes tipos:

a) 166 Esvaentes - conjunto de municípios que agregava 6 milhões de habitantes e "que tiveram fortes quedas populacionais relativas (e muitas vezes absolutas)";

b) 152 Letárgicos - que contavam com uma população de 6,6 milhões de habitantes e "que também tiveram perdas relativas, mas assim mesmo cresceram em termos absolutos em compassos não muito distantes ao de seus respectivos estados"; e

c) 249 Atraentes - com população de 9 miIhões de habitantes que "tiveram crescimentos superiores aos de seus estados". (VEIGA et al., 2001, p. 20).

Já os 4.485 municípios rurais abarcaram em seus territórios uma população de 51,6 milhões de habitantes em 2000 , ou $40 \%$ da população residente fora dos espaços metropolitanos e centros urbanos, e 30,42\% do total da população brasileira. Assim como os municípios Rurbanos, os municípios Rurais foram divididos nos seguintes tipos: a) 2.025 Esvaentes - com uma população de 19,7 milhões de habitantes; b) 1.351 Letárgicos - que tinham um conjunto de 17,5 milhões de habitantes; e c) 1.109 Atraentes - que computaram 14,4 miIhões de habitantes. 
De acordo com os autores, essas duas categorias de municípios tinham uma população média em 2000 de 9.729 habitantes para os municípios Esvaentes. Já o tamanho médio para os municípios Letárgicos foi de 12.866 habitantes e para os municípios Atraentes estes valores eram de 12.969 .

No que se refere à densidade demográfica (hab./ $\mathrm{km}^{2}$ ), essas duas categorias de municípios alcançaram, em 2000, uma densidade mediana de 18,66 hab/ $\mathrm{km}^{2}$ para os municípios Esvaentes, mediana de 20,85 hab/ $\mathrm{km}^{2}$ nos municípios Letárgicos e o valor para os municípios Atraentes foi de 19,69 hab/ $/ \mathrm{km}^{2}$.

O que se pode observar é que os menores valores máximos do tamanho da população e densidade demográfica ocorreram nos municípios do tipo Atraentes. (VEIGA et al., 2001, p. 20-22).

Ainda de acordo com TAVARES (1999, p. 83) e BIANCHINI (2001, p. 93), entre as duas últimas décadas do século XX, e principalmente na última, o Paraná sofreu diferentes dinâmicas de crescimento da população. No período de 1991-2000 (Tabela 2), dos 399 municípios do Estado, 318 ou $80 \%$ tinham menos de 20 mil habitantes, nos quais se concentravam $26,9 \%$ da população, correspondendo a $62 \%$ da população rural do Estado. A população desses pequenos municípios estava concentrada em $41 \%$ na área rural e 59\% na área urbana, de acordo com os atuais critérios que definem os espaços rural e urbano. Em 1991, esses valores eram de $51 \%$ e $49 \%$, respectivamente. Uma das explicações para a queda da população rural foi a criação de 81 novos municípios no período, quando muitas áreas rurais se transformaram em áreas urbanas.

Do conjunto de 318 municípios Atraentes com menos de 20 mil habitantes, 41 cresceram acima da média do Estado, 89 municípios Letárgicos apresentaram taxas positivas de crescimento, porém abaixo da média do Estado, e 188 Esvaentes perderam população em termos absolutos. A redução da população ficou em 3,5\%, na década, no conjunto dos 318 municípios com menos de 20 mil habitantes em todo o Estado.

Também existem outras tipologias para diferentes recortes espaciais, para caracterizar o espaço urbano/rural e que merecem uma análise sumária.
No entendimento de CROMARTIE e SWANSON, citado por GRAZIANO DA SILVA (1997, p. 119), os conceitos básicos para definir o que é rural não mudaram muito ao longo do tempo. Todavia, afirmam que

\begin{abstract}
"o tamanho da população, sua densidade e sua localização não foram ainda mapeadas numa escala suficiente detalhada para capturar a crescente complexidade dos padrões de povoamento modernos. Em funções disso, a escolha das unidades geográficas apropriadas para a construção de um "continuum rural-urbano" afeta tanto o rigor da análise como a sua aplicabilidade a determinado conjunto de questões. Evidentemente que a desagregação facilita a obtenção de populações mais homogêneas, considerados determinados atributos". (GRAZIANO DA SILVA, 1997, p. 119).
\end{abstract}

GRAZIANO DA SILVA (1997, p. 118, 119) diz que os americanos John CROMARTIE e Linda SWANSON, com base em critérios que buscaram combinar padrões demográficos tradicionais como os fluxos das atividades econômicas, envolvendo tanto a produção de bens e serviços quanto o deslocamento dos próprios trabalhadores, desdobraram o corte metropolitano/não-metropolitano do ERS/USDA (usado como equivalente ao corte de urbano/rural, embora se reconheça que o primeiro tem uma definição mais precisa), utilizando dados desagregados por distrito censitário, que é uma unidade menor que a dos condados, tradicionalmente utilizada como a menor unidade de divulgação dos dados censitários americanos. Os autores propuseram cinco categorias para identificar o que chamaram de "um continuum rural/urbano":

1 - Centro Metropolitano - "região que possui pelo menos $50 \%$ da população em áreas urbanizadas";

2 - Entorno Metropolitano - "regiões que possuem elevada integração econômica e social com o centro, medida pelos fluxos permanentes de trabalhadores, produtos e serviços entre eles e que exibem características similares ao centro em relação a densidade

TABELA 2 - TAXA DE CRESCIMENTO ANUAL DE POPULAÇÃO RESIDENTE, SEGUNDO MUNICÍPIOS COM MENOS DE 20 MIL HABITANTES - PARANÁ - 1991-2000

\begin{tabular}{lcc}
\hline \multicolumn{1}{c}{ Municípios } & $\mathrm{N}^{\circ}$ & $\%$ \\
\hline > Estado - Atraentes & 41 & 12,89 \\
< Estado - Letárgicos & 89 & 27,99 \\
Negativo - Esvaentes & 188 & 59,12 \\
Total & 318 & 100,00 \\
\hline
\end{tabular}

Fonte: Censo Demográfico 2000 - IBGE. 
populacional, percentagem urbana e taxa de crescimento da década anterior";

3 - Adjacências não-metropolitanas - "regiões fisicamente adjacentes mas que possuem no maximo $2 \%$ da sua força de trabalho deslocando-se continuamente para as áreas metropolitanas";

4 - Não-adjacentes com cidade - "regiões não incluídas nas categorias anteriores mas que possuem um núcleo urbano de pelo menos 10 mil habitantes"; e

5 - Não-adjacentes sem cidade - "demais regiões não classificadas nas anteriores".

Atualmente, no Brasil, uma nova concepção de análise do espaço rural brasileiro vem sendo elaborada pela UNICAMP, a partir do chamado "Projeto Rurbano", existindo já vários trabalhos publicados a respeito. Entre os participantes desse projeto encontram-se os pesquisadores José Graziano da Silva (1996, 1997, 1998 e 1999), Lauro Mattei (1997), que realiza pesquisa sobre a "Pluriatividade no contexto do desenvolvimento rural catarinense", Ângela Kageyama (1999 e 2000), Sergio Schneider (1999), em "As atividades rurais não-agrícola e as transformações do espaço rural: perspectivas recentes", Marcelino de Souza (1999), em "Caracterização e evolução das ocupações das pessoas e das famílias agrícolas e rurais no contexto paranaense: uma análise a partir dos dados das PNADs", e o trabalho de Valter Bianchini (2001) em "Estratégias para o desenvolvimento rural", In: Série textos para discussão $\mathrm{n}^{\circ} 2$ do MDA/NEAD.

Concorda-se com os pesquisadores que houve uma transformação no rural brasileiro, com o surgimento de regiões dinâmicas, que assumem "novas funções". "O rural, [...] além de sua função agrícola, representa hoje também local de moradia, de lazer, de serviços e de emprego para pessoas ocupadas em atividades nãoagrícolas. Ou seja, embora muita gente ainda acredite que quem mora na zona rural está ocupada em atividades agropecuárias, isso há muito deixou de ser verdade". (GRAZIANO DA SILVA, 1996, p. 179). Contudo, é preciso ressaltar que alguns pesquisadores trabalham com os dados da Pesquisa Nacional por Amostra de Domicílios - PNAD, de forma acrítica. Em nenhum momento os autores questionam os conceitos e metodologia utilizados pelo IBGE para definir o que é urbano e rural, deixando de lado um significativo número de "barrados no baile, os excluídos, os descamisados, ou os pobres do campo ou qualquer nome que se possa dar a essa população, marginal do ponto de vista das necessidades internas da acumulação do sistema". (GRAZIANO DA SILVA, 1996, p. 178).
Portanto, entende-se que a delimitação do espaço rural brasileiro, hoje, deveria estar pautada nos seguintes itens: a) transpor as barreiras político-administrativas-jurídicas, para por fim à "discrepância gritante", usando o termo muito feliz de BERNARDES, SANTOS e NALCACER (1993), que vem desde o Decreto-Lei 311/ 38; b) não deixar perpetuar a abordagem dicotômica rural/urbano ou campo/cidade, que atualmente fundamenta o planejamento e as intervenções políticas no país, com política de desenvolvimento regional, local, rural, ou qualquer outra palavra que só atrapalha a noção do processo mais amplo, que leva em conta acima de tudo, a criação de novas oportunidades no espaço territorial como um todo, de um município ou conjunto de municípios (microrregião), para que sejam alcançadas as transformações desejáveis; (GRAZIANO DA SILVA, 2001, p. 15) e, c) que sejam levados em consideração os critérios de densidade, tamanho da população, vocação social, econômica, cultural, história de cada recorte territorial rural.

\section{CONCLUSÃO}

Tendo isso em vista, a análise da formação dos municípios e das fronteiras normativas/demográficas e sociológica do espaço urbano e rural brasileiro permitiu constatar que há uma anomalia nas atuais legislações de criação dos municípios brasileiros e delimitação dos seus perímetros urbanos.

À luz desse quadro, e levando em consideração as variáveis apresentadas anteriormente para definir um município rural, pode-se construir uma tipologia para classificar os municípios rurais brasileiros que incorpore os critérios analisados neste trabalho e que mostrese mais adequada para caracterizar a trama socioespacial da área de estudo. Tal tipologia alternativa consiste nas seguintes categorias:

i) município rural dinâmico, onde se tem a predominância da pluriatividade nos estabelecimentos agropecuários e/ou entre os membros das famílias produtoras da agropecuária;

ii) município rural moderno, onde se tem a predominância das atividades dos setores secundário e terciário da economia no espaço rural e uma agropecuária tecnificada;

iii) município rural vivo atraente, onde há o predomínio de atividades agropecuárias na PEA e na geração de renda e na qual a população rural esteja em crescimento desde 1991; 
iv) município rural vivo letárgico, em que há o predomínio de atividades agropecuárias na geração de renda e na PEA, mas, em razão da baixa rentabilidade dessas atividades no local, a população rural e a participação da agropecuária na PEA mantêmse nos mesmos patamares desde 1991;

v) município rural vivo esvaente, onde há o predomínio de atividades agropecuárias na geração de renda e na PEA, mas a baixa rentabilidade dessas atividades tem levado a população rural e a PEA agropecuária a uma diminuição desde 1991;

vi) município rural turístico, onde há o predomínio do turismo rural e do ecoturismo; e

vii) município rural ecológico, onde há o predomínio de unidades de conservação ambiental (federais, estaduais, municipais e particulares).

\section{REFERÊNCIAS}

ABRAMOVAY, R. Funções e Medidas da Ruralidade no Desenvolvimento Contemporâneo. Rio de Janeiro: IPEA, (Texto para Discussão n. 702), 2000.

Bases para a formulação da política brasileira de desenvolvimento rural: agricultura familiar e desenvolvimento territorial. Brasília: ago. 1998. Mimeografado.

O capital social dos territórios, repensando o desenvolvimento rural. In: CONGRESSO DA SOCIEDADE BRASILEIRA DE ECONOLIA POLÍTICA, 4., 1999, Porto Alegre. Anais... Porto Alegre, 1999.

BERNARDES, L. M. C.; SANTOS, S. R. L.; WALCACER, F. C. Redefinição do conceito de urbano e rural. Curitiba: Ipardes, 1993. Mimeografado.

BIANCHINI, V. Estratégias para o desenvolvimento rural. In: Brasil rural precisa de uma estrágia de desenvolvimento. Brasília: MDA/ Nead 2001. p. 71-108. Textos para Discussão, 2.

BRASIL. Constituição da República Federativa do Brasil. São Paulo: Atlas, 1998.

CARNEIRO, M. J. Ruralidade: novas identidades em construção. In: CONGRESSO BRASILEIRO DE ECONOMIA E SOCIOLOGIA RURAL, 35., 1997, Brasília. Anais..., p. 147-185.

Camponeses, agricultura \& pluriatividade. Rio de Janeiro: Contra Capa, 1998.

CIGOLINI, A. A. A fragmentação do território em municípios: um resgate histórico. Revista Paranaense de Geografia, Curitiba: AGB-Seção Curitiba/UTP, n. 5, p. 55-65, 2000.

FARIA, V. Desenvolvimento, urbanização e mudanças na estrutura do emprego: a experiência brasileira dos últimos trinta anos. In: SORJ, B.; ALMEIDA, M. H. T. de. (Orgs.). Sociedade e política no Brasil pós-64. 2. ed. São Paulo: Brasiliense, 1984. p. 118-163.

FERREIRA, A. D. D. O rural como categoria sociológica. Revista de Sociologia e Política, Curitiba: UFPR, n. 12, p. 147150, jun. 1999.
GRAZIANO DA SILVA, J. et al. O novo rural brasileiro. In: SHIKI, S. et al. Agricultura, meio ambiente e sustentabilidade do cerrado brasileiro. Uberlândia, 1997, p. 75-100.

A nova dinâmica da agricultura Brasileira. Campinas: Unicamp, 1996.

Sobre a delimitação do rural e do urbano no Brasil: testando as aberturas geográficas das novas PNADS. In: CONGRESSO BRASILEIRO DE ECONOMIA E SOCIOLOGIA RURAL, 35., 1997a, Brasília. Anais..., Brasília, 1997. p. 114-146.

Quem precisa de uma estratégia de desenvolvimento? Brasil rural precisa de uma estrágia de desenvolvimento. Brasília: MDA/Nead 2001. p. 5-52. Textos para Discussão, 2.

IBAM. Gênese dos municípios brasileiros. Disponível em:<http://www.ibam.org.br> Acesso em 6 nov. 2001.

IBGE. XI Recenseamento geral do Brasil: Manual da delimitação dos setores 2000. Rio de Janeiro: IBGE, 1998.

IPEA/IBGE/NSUR-Unicamp. Caracterização e tendências da rede urbana do Brasil. Campinas: Instituto de Economia da Unicamp, 1999.

KARAM, K. F. Agricultura Orgânica: estratégia para uma nova ruralidade. Curitiba, 2001. 232 f. Tese (Doutorado em Meio Ambiente e Desenvolvimento) - Pró-Reitoria de Pesquisa e Pós-Graduação, Universidade Federal do Paraná.

PEREIRA DE QUEIROZ, M. I. O campesinato brasileiro. Petrópolis: Vozes, 1973.

SARACENO, E. The modern functions of small farm systems: an Italian experience. Sociologia Ruralis, v. 34, n. 4, p. 328358, 1994.

TAVARES, L. A. A contribuição da citricultura no processo urbano de Cêrro Azul. Curitiba, 1999. 119 f. Monografia (Graduação em Geografia) - Departamento de Geografia, Setor de Ciências da Terra, Universidade Federal do Paraná.

VEIGA, J. E. da. et al. Brasil rural precisa de uma estrágia de 
TAVARES, L. A. As fronteiras físicas do espaço rural: uma concepção...

desenvolvimento. Brasília: MDA/Nead, 2001. Textos para Discussão, 1.

VILELA, S. L. O. Globalização e emergência de múltiplas ruralidades: reprodução social de agricultures via produtores para nichos de mercado. Campinas, 1999. 205 f. Tese (Doutorado em Ciências Sociais) - Departamento de Ciências Sociais do Instituto de Filosofia e Ciências Humanas, Universidade Estadual de Campinas.
WANDERLEY, M. N. B. A emergência de uma nova ruralidade nas sociedades modernas avançadas: o "rural" como espaço singular e ator coletivo. Estudos Sociedade e Agricultura. Rio de Janeiro: UFRJ, n. 15, out. 2000a, p. 87-144.

Urbanização e ruralidade: relações entre a pequena cidade e o mundo rural e estudo preliminar sobre os pequenos municípios em Pernambuco. Recife: 2000. Mimeografado. Olhares sobre "rural" brasileiro. Recife: Universidade Federal de Pernambuco, out. 1999. 